\title{
ARTICLE
}

Chronic myelogenous leukemia

\section{Long-term outcomes with frontline nilotinib versus imatinib in newly diagnosed chronic myeloid leukemia in chronic phase: ENESTnd 10-year analysis}

\author{
Hagop M. Kantarjian $\mathbb{D}^{1} \cdot$ Timothy P. Hughes ${ }^{2,3} \cdot$ Richard A. Larson $\mathbb{D}^{4} \cdot$ Dong-Wook Kim $\mathbb{1}^{5} \cdot$ Surapol Issaragrisil ${ }^{6} \cdot$ \\ Philipp le Coutre ${ }^{7}$ Gabriel Etienne ${ }^{8}$. Carla Boquimpani ${ }^{9,10} \cdot$ Ricardo Pasquini $^{11} \cdot$ Richard E. Clark $\mathbb{D}^{12}$. \\ Viviane Dubruille $^{13} \cdot$ Ian W. Flinn ${ }^{14} \cdot$ Slawomira Kyrcz-Krzemien $^{15} \cdot$ Ewa Medras $^{16} \cdot$ Maria Zanichelli $^{17}$. \\ Israel Bendit ${ }^{18} \cdot$ Silvia Cacciatore $^{19} \cdot$ Ksenia Titorenko $^{20} \cdot$ Paola Aimone $^{19} \cdot$ Giuseppe Saglio $^{21} \cdot$ Andreas Hochhaus $^{22}$
}

Received: 2 October 2020 / Revised: 2 November 2020 / Accepted: 2 December 2020 / Published online: 7 January 2021

(c) The Author(s) 2021. This article is published with open access

\begin{abstract}
In the ENESTnd study, with $\geq 10$ years follow-up in patients with newly diagnosed chronic myeloid leukemia (CML) in chronic phase, nilotinib demonstrated higher cumulative molecular response rates, lower rates of disease progression and CML-related death, and increased eligibility for treatment-free remission (TFR). Cumulative 10-year rates of MMR and $\mathrm{MR}^{4.5}$ were higher with nilotinib (300 mg twice daily [BID], $77.7 \%$ and $61.0 \%$, respectively; $400 \mathrm{mg} \mathrm{BID}, 79.7 \%$ and $61.2 \%$, respectively) than with imatinib ( $400 \mathrm{mg}$ once daily [QD], $62.5 \%$ and $39.2 \%$, respectively). Cumulative rates of TFR eligibility at 10 years were higher with nilotinib (300 mg BID, 48.6\%; $400 \mathrm{mg}$ BID, 47.3\%) vs imatinib (29.7\%). Estimated 10 -year overall survival rates in nilotinib and imatinib arms were $87.6 \%, 90.3 \%$, and $88.3 \%$, respectively. Overall frequency of adverse events was similar with nilotinib and imatinib. By 10 years, higher cumulative rates of cardiovascular events were reported with nilotinib (300 mg BID, 16.5\%; $400 \mathrm{mg}$ BID, 23.5\%) vs imatinib (3.6\%), including in Framingham low-risk patients. Overall efficacy and safety results support the use of nilotinib $300 \mathrm{mg}$ BID as frontline therapy for optimal longterm outcomes, especially in patients aiming for TFR. The benefit-risk profile in context of individual treatment goals should be carefully assessed.
\end{abstract}

\section{Introduction}

Nilotinib is a second-generation BCR-ABL1 tyrosine kinase inhibitor (TKI) widely used for the treatment of patients with newly diagnosed Philadelphia chromosome-positive $(\mathrm{Ph}+)$ chronic myeloid leukemia in chronic phase (CML-CP) or imatinib-resistant or imatinib-intolerant $\mathrm{Ph}+\mathrm{CML}$ in $\mathrm{CP}$ or

These authors contributed equally: Hagop M. Kantarjian, Timothy P. Hughes

These authors jointly supervised this work: Giuseppe Saglio, Andreas Hochhaus

Supplementary information The online version of this article (https:// doi.org/10.1038/s41375-020-01111-2) contains supplementary material, which is available to authorized users.

Hagop M. Kantarjian

hkantarjian@mdanderson.org

Extended author information available on the last page of the article accelerated phase (AP) [1-3]. The approved nilotinib dose for adult patients with newly diagnosed $\mathrm{Ph}+\mathrm{CML}-\mathrm{CP}$ is $300 \mathrm{mg}$ twice-daily, and for those with resistant or intolerant $\mathrm{Ph}+\mathrm{CML}-\mathrm{CP}$ and CML-AP, the dose is $400 \mathrm{mg}$ twice-daily $[2,3]$.

Throughout the first 5 years of follow-up in the pivotal phase 3 ENESTnd (Evaluating Nilotinib Efficacy and Safety in Clinical Trials-Newly Diagnosed Patients) study, treatment with nilotinib resulted in higher rates of major molecular response (MMR; $B C R-A B L 1 \leq 0.1 \%$ on the International Scale $\left.\left[B C R-A B L 1^{\mathrm{IS}}\right]\right)$ and deep molecular response (DMR; including $\mathrm{MR}^{4}\left[B C R-A B L 1^{\mathrm{IS}} \leq 0.01 \%\right]$ and $\mathrm{MR}^{4.5}[B C R$ $\left.A B L 1^{\mathrm{IS}} \leq 0.0032 \%\right]$ ) over imatinib as frontline therapy for newly diagnosed CML-CP $[4,5]$. In the primary endpoint analysis, rates of MMR at 12 months were $44 \%$ with nilotinib 300-mg twice-daily, $43 \%$ with nilotinib 400-mg twice-daily, and $22 \%$ with imatinib (400-mg once-daily, $P<0.001$ for both comparisons) [4]. With 5 years of follow-up, 54\% of patients on nilotinib 300-mg twice-daily and $52 \%$ of patients on nilotinib 400-mg twice-daily achieved $\mathrm{MR}^{4.5}$ compared 
with $31 \%$ of patients on imatinib $(P<0.0001$ for both comparisons) [5]. Lower rates of progression to $\mathrm{AP} / \mathrm{blast}$ phase (BP) with nilotinib versus imatinib were observed throughout the first 5 years of follow-up [5].

The 5-year ENESTnd analysis showed a higher frequency of cardiovascular events (CVEs) with nilotinib than with imatinib, particularly in the nilotinib 400-mg twicedaily arm. Baseline Framingham general cardiovascular risk scores were predictive of patients' risk of developing a CVE during nilotinib therapy, suggesting that patients at risk of developing CVEs during therapy with TKIs might be identifiable at baseline and that active monitoring and treatment of comorbidities and cardiovascular risk factors in all patients are needed [5]. Overall, the benefit-risk profile of nilotinib as frontline therapy for patients with CML-CP remained positive [4-8].

Patients with CML on TKI therapy have a life expectancy comparable to that of the general population $[9,10]$ and are likely to continue treatment for many years, possibly decades $[11,12]$. Patients may develop comorbidities with age [5, 13-15] and may also develop distinct, longterm, TKI therapy-related adverse events (AEs) [5, 16]. Managing comorbidities and AEs is an important aspect of long-term treatment $[5,10,11]$. For patients achieving sustained DMR, treatment-free remission (TFR) may be an additional treatment goal $[10,12,17]$.

To allow a comprehensive assessment of the long-term benefits and risks of nilotinib and imatinib in patients with CML-CP, the final results from ENESTnd after $\geq 10$ years of follow-up are reported here.

\section{Methods}

\section{Study design and patients}

Study design and eligibility criteria for ENESTnd (NCT00471497) have been described previously [4-8]. Briefly, patients with newly diagnosed CML-CP were randomized to receive nilotinib 300-mg twice-daily $(n=282)$, nilotinib 400-mg twice-daily ( $n=281$ ), or imatinib 400-mg once-daily $(n=283)$ in the core phase. Some patients who discontinued their assigned core treatment due to suboptimal response, treatment failure, or progressive disease could enter the extension phase of the study (Supplementary Fig. 1; Supplementary Table 1) [6].

\section{Study endpoints and assessments}

Long-term endpoints included cumulative rates of MMR, $\mathrm{MR}^{4}$, and $\mathrm{MR}^{4.5}$, progression to $\mathrm{AP} / \mathrm{BP}$, overall survival (OS), progression-free survival (PFS), and safety. Molecular responses were assessed by $B C R-A B L 1 / A B L 1$ transcript ratios using real-time quantitative polymerase chain reaction (RT-qPCR) at a central laboratory (MolecularMD, Portland, OR, USA) standardized to the IS. Data on progression to $\mathrm{AP} / \mathrm{BP}$ and survival were prospectively collected as described previously [5]. Time to progression to $\mathrm{AP} / \mathrm{BP}$ was defined as time from randomization until progression to $\mathrm{AP} / \mathrm{BP}$ or death due to advanced $\mathrm{CML}$, whichever occurred first. Death due to advanced CML was defined as any death (at any time) for which the principal cause was reported by the investigator as "study indication" (i.e., due to CML) or, if subsequent to documented progression to $\mathrm{AP} / \mathrm{BP}$, any death for which the cause was reported as "unknown" or was not reported. OS was defined as time from randomization until death due to any cause. PFS was defined as time from randomization until progression to $\mathrm{AP} / \mathrm{BP}$ or death due to any cause. Rates of freedom from progression to AP/BP, PFS, and OS on study considered events that occurred during core or extension treatment and those that occurred during follow-up after discontinuation of core or extension treatment. Further details on the study protocol and assessment schedule have been published previously $[4,5]$.

\section{Statistical analysis}

The efficacy and safety data presented here are based on a final analysis of the study following the last patient's last visit (21 August 2019), when all patients had completed $\geq 10$ years of treatment (in the core or extension phase) or discontinued earlier. All analyses presented here included data from the core phase only, with the exception of survival and progression "on study" analyses, which also included data from the extension phase. Data from the extension phase are reported based on treatment initially assigned to patients during core phase. For analyses combining data from the 2 nilotinib arms, extension phase data for patients who switched from nilotinib 300-mg twice-daily to nilotinib 400-mg twice-daily were also included.

Efficacy analyses included the intent-to-treat population (all randomized patients; $N=846$ ). Analysis of molecular response at 10 years according to molecular response at 5 years included only patients with typical $B C R-A B L 1$ transcripts at baseline who remained on treatment at 5 years based on a 3-month time window (nilotinib 300-mg twicedaily arm, $n=183$; nilotinib 400-mg twice-daily arm, $n=$ 188; imatinib arm, $n=153$ ) (Fig. 1). Response rates were compared using the Cochran-Mantel-Haenszel test stratified by Sokal risk group. Clopper-Pearson 95\% 2-sided CIs for response rates are shown. Time-to-event variables were analyzed using the Kaplan-Meier (KM) method and were compared between groups using log-rank tests stratified by Sokal risk group. Hazard ratios and 95\% 2-sided CIs were derived from a Cox model stratified by Sokal risk group; 
A

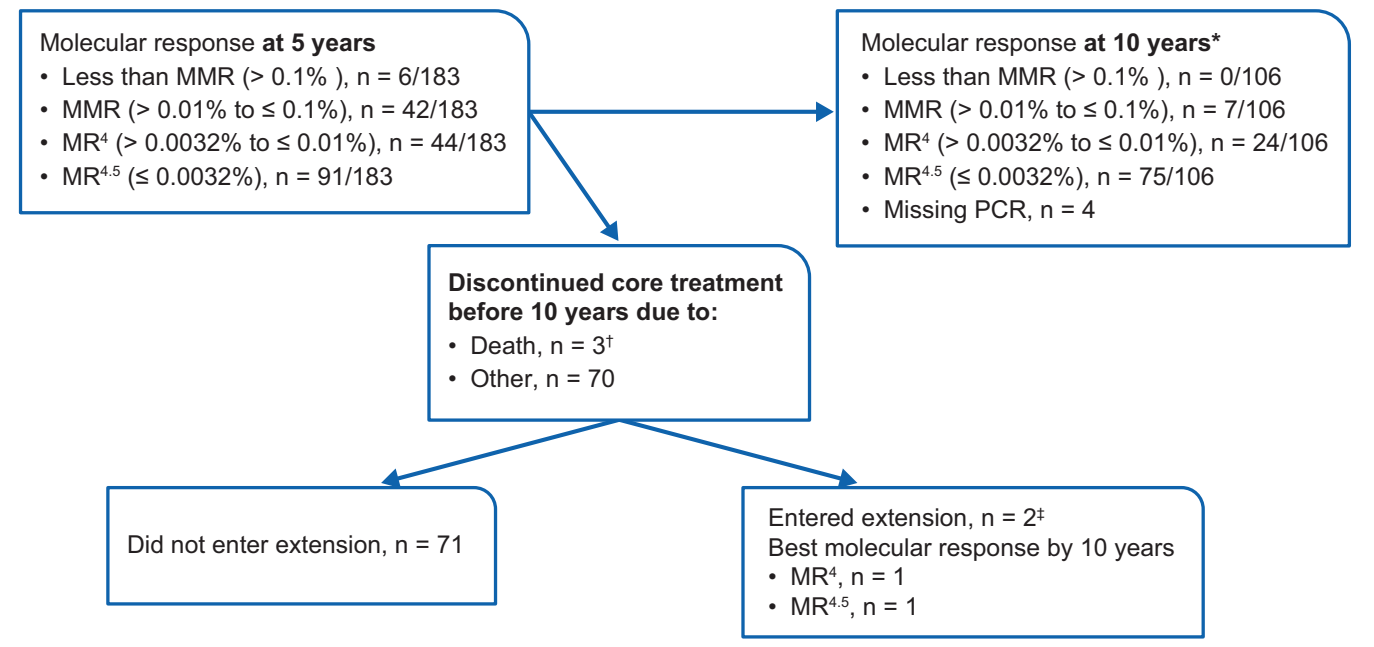

B
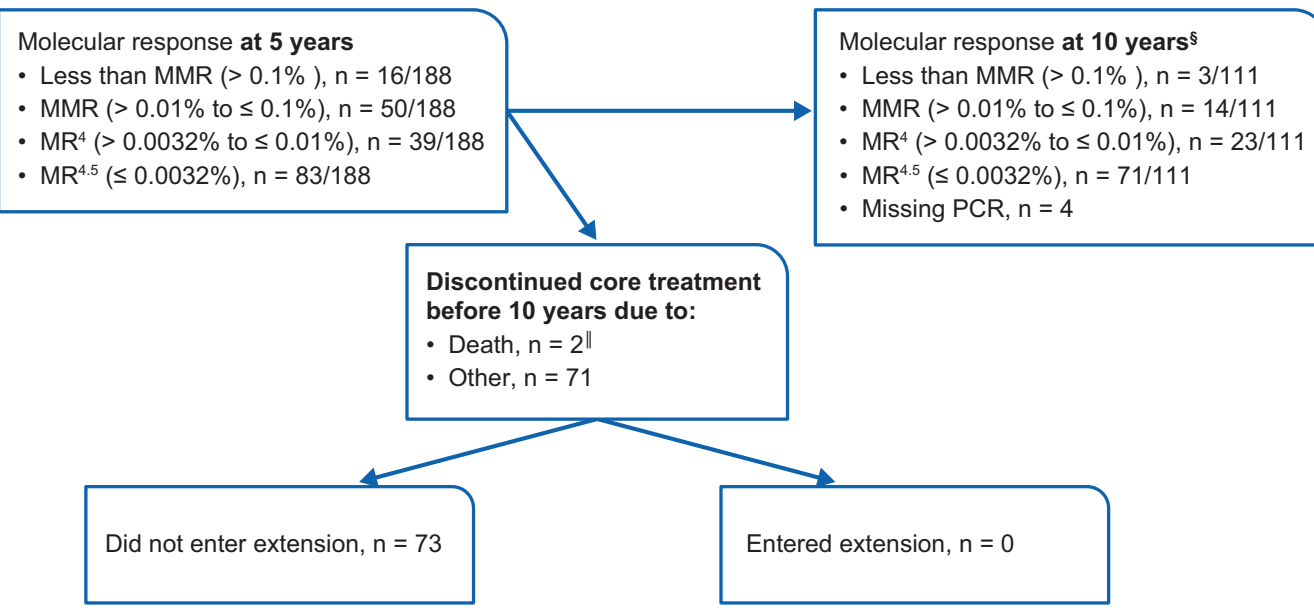

C
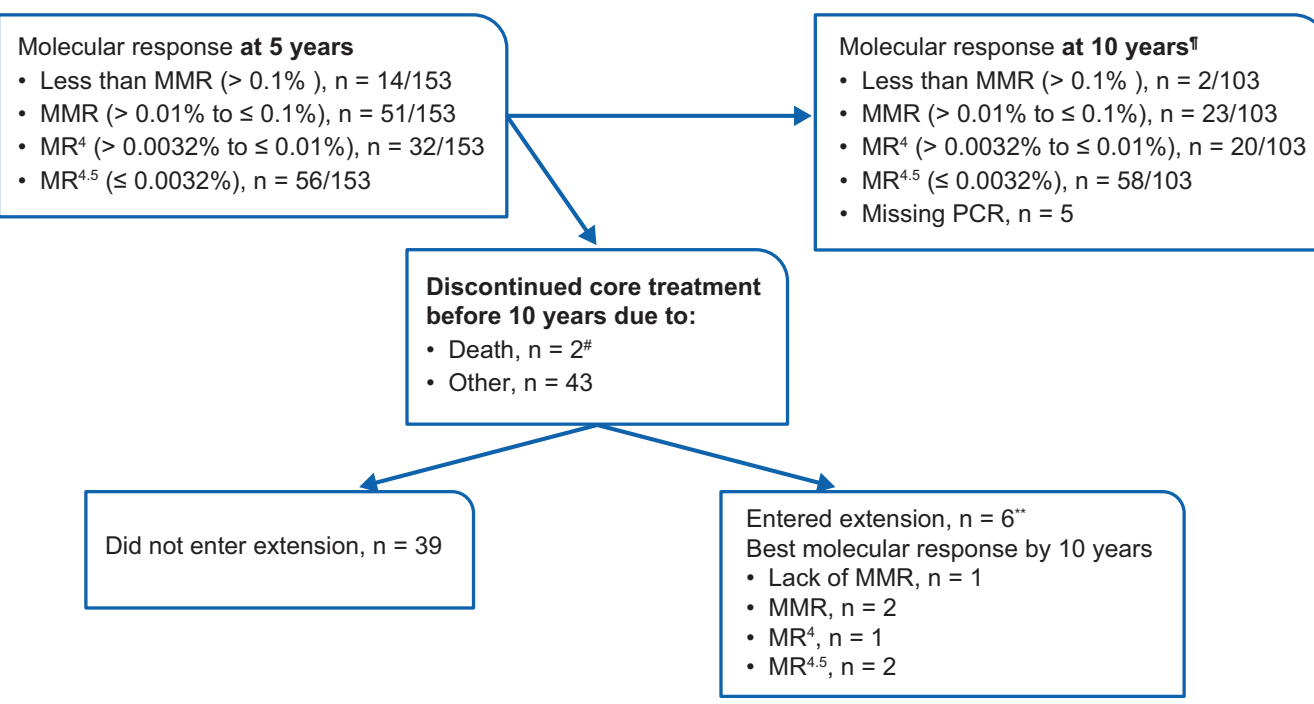

95\% CIs for KM estimates were derived using the standard error calculated with Greenwood's formula. Nominal 2sided $P$ values, when provided, are for descriptive purposes only without multiplicity adjustments; therefore, no formal statistical claim can be made, and statistical interpretation should be made with caution. Safety analyses included all 
Fig. 1 Change in molecular response from 5 years to 10 years by molecular response at 5 years in patients with evaluable RQ-PCR at 5 years. A Nilotinib $300 \mathrm{mg}$ twice daily. B Nilotinib $400 \mathrm{mg}$ twice daily. C Imatinib $400 \mathrm{mg}$ twice daily. ${ }^{*}$ Of patients without MMR at 5 years, $33.3 \%(2 / 6)$ achieved MMR or better at 10 years. Of patients without $\mathrm{MR}^{4}$ at 5 years, $43.8 \%(21 / 48)$ achieved $\mathrm{MR}^{4}$ or better at 10 years. Of patients without $\mathrm{MR}^{4.5}$ at 5 years, $38.0 \%$ (35/92) achieved $\mathrm{MR}^{4.5}$ at 10 years. ${ }^{\dagger}$ All 3 patients were in $\mathrm{MR}^{4.5}$ at 5 years but died before 10 years ( 1 due to cardiac arrest, 1 due to multiple organ dysfunction syndrome, and 1 due to pneumonia) while still in $\mathrm{MR}^{4.5}$. ${ }^{\ddagger}$ Both patients were in $\mathrm{MR}^{4.5}$ at 5 years but were not in MMR before entering the extension phase. ${ }^{\S}$ Of patients without MMR at 5 years, $43.8 \%(7 / 16)$ achieved MMR or better at 10 years. Of patients without $\mathrm{MR}^{4}$ at 5 years, $37.9 \%(25 / 66)$ achieved $\mathrm{MR}^{4}$ or better at 10 years. Of patients without $\mathrm{MR}^{4.5}$ at 5 years, $28.6 \%(30 / 105)$ achieved $\mathrm{MR}^{4.5}$ at 10 years. "One patient was in $\mathrm{MR}^{4.5}$ at 5 years and in $\mathrm{MR}^{4}$ before death due to myocardial infarction. The other patient was in $\mathrm{MR}^{4}$ at 5 years and before death due to an unknown reason. ${ }^{\text {IO }}$ Of patients without MMR at 5 years, $50 \%(7 / 14)$ achieved MMR or better at 10 years. Of patients without $\mathrm{MR}^{4}$ at 5 years, $33.8 \%(22 / 65)$ achieved $\mathrm{MR}^{4}$ or better at 10 years. Of patients without $\mathrm{MR}^{4.5}$ at 5 years, $22.7 \%(22 / 97)$ achieved $\mathrm{MR}^{4.5}$ at 10 years. "Both patients were at MMR at 5 years but died before 10 years ( 1 due to cardiac arrest and 1 due to pneumonia), while still in MMR. ${ }^{* *}$ Two patients achieved $\mathrm{MR}^{4.5}, 1$ achieved $\mathrm{MR}^{4}$, 2 achieved MMR, and 1 had responses less than MMR in the extension phase.

patients who received $\geq 1$ dose of study drug (nilotinib 300mg twice-daily arm, $n=279$; nilotinib 400-mg twice-daily arm, $n=277$; imatinib arm, $n=280$ ). CVE rates for each treatment group were determined by using cumulative events over time as well as the KM method. Analyses were also performed by combining data from both nilotinib arms to compare responses and outcomes achieved with nilotinib $(n=563)$ versus imatinib $(n=283)$, regardless of dose. The extent of exposure was analyzed comparing exposures in the combined safety population of both nilotinib arms $(n=$ 556) versus the imatinib arm $(n=280)$.

Eligibility for TFR, per criteria used in ENESTfreedom [18], was defined as achieving $M^{4.5}$ or better after $\geq 2$ years of treatment and then maintaining sustained DMR for $\geq 1$ year (defined as having no RT-qPCR assessment showing a response level worse than $\mathrm{MR}^{4}$, a maximum of 2 assessments with response level of $\mathrm{MR}^{4}$, and $\mathrm{MR}^{4.5}$ or better in the last assessment).

\section{Results}

\section{Patients}

By the date of the last patient's last visit, 107 (37.9\%), 99 $(35.2 \%)$, and $99(35.0 \%)$ patients in the nilotinib 300-mg twice-daily, nilotinib 400-mg twice-daily, and imatinib arms, respectively, completed the study and were treated for $\geq 10$ years overall. The most common reasons for discontinuation from core treatment in all 3 arms included
AEs, withdrawal of consent, and suboptimal response or treatment failure (Supplementary Table 1). The median duration of core treatment was $82.8,87.5$, and 64.0 months, respectively, in the nilotinib $300-\mathrm{mg}$ twice-daily, nilotinib 400-mg twice-daily, and imatinib arms. Twenty-six (9.2\%), $3(1.1 \%)$, and $48(17.0 \%)$ patients, respectively, discontinued core treatment and entered the extension phase of the study. Among the 77 patients who entered the extension phase, 12,2 , and 21 , respectively, completed their planned treatment, and 14, 1, and 27 discontinued early.

One hundred seventy-one (61.3\%), $182(65.7 \%)$, and 146 $(52.1 \%)$ patients, respectively, in the nilotinib $300-\mathrm{mg}$ twice-daily, nilotinib 400-mg twice-daily, and imatinib arms remained on treatment for $\geq 5$ years; and 101 (36.2\%), $87(31.4 \%)$, and $90(32.1 \%)$ patients, respectively, received treatment for $\geq 10$ years.

\section{Long-term outcomes}

Fewer progressions to AP/BP were observed with nilotinib than with imatinib (Table 1). A total of 6,4 , and 11 progressions to $\mathrm{AP}$ and 6,6 , and 14 progressions to $\mathrm{BP}$ were reported on study in the nilotinib 300-mg twice-daily, nilotinib 400-mg twice-daily, and imatinib arms, respectively. Among those who progressed to BP, 2, 3, and 4 patients, respectively, had progressed to AP first. Overall, a total of 11,7 , and 24 progressions to $\mathrm{AP} / \mathrm{BP}$, including CML-related deaths, were reported on study in the nilotinib 300-mg twice-daily, nilotinib 400-mg twice-daily, and imatinib arms, respectively, including 1,1 , and 5, respectively, after the first 5 years, all of which occurred during the follow-up period after core or extension treatment discontinuation due to reasons other than progression. After the 5-year analysis, no new progressions to AP/BP on core treatment were observed.

The estimated 10-year rates of freedom from progression to $\mathrm{AP} / \mathrm{BP}$ were higher in the nilotinib arms than the imatinib arm among patients $<60$ years old at baseline and were comparable across arms in patients $\geq 60$ years old at baseline. In an analysis according to baseline Sokal risk score, the estimated 10-year rates of freedom from progression to AP/BP were comparable across arms in the low Sokal risk group and higher in the nilotinib arms in the intermediate and high Sokal risk groups (Table 1).

At 10 years, the rates of PFS and OS on study were similar across the 3 arms (Supplementary Fig. 2) and were also comparable in the analysis conducted by Sokal score, with the highest rates reported in patients with low Sokal risk (Tables 2 and 3 ).

In an analysis of 10-year outcomes according to age at baseline, the estimated 10 -year OS rates in the nilotinib 300-mg twice-daily, nilotinib 400-mg twice-daily, and imatinib arms were $92.7 \%, 94.5 \%$, and $89.7 \%$, respectively, 
Table 1 Progression to AP/BP.

\begin{tabular}{|c|c|c|c|}
\hline & $\begin{array}{l}\text { Nilotinib } 300 \mathrm{mg} \\
\text { twice daily }\end{array}$ & $\begin{array}{l}\text { Nilotinib } 400 \mathrm{mg} \\
\text { twice daily }\end{array}$ & $\begin{array}{l}\text { Imatinib } 400 \mathrm{mg} \\
\text { once daily }\end{array}$ \\
\hline Progression to AP/BP on study, $n^{\mathrm{a}}$ & 282 & 281 & 283 \\
\hline Progression to AP/BP, $n^{\mathrm{b}}$ & 11 & 7 & 24 \\
\hline \multicolumn{4}{|l|}{$\begin{array}{l}\text { Estimated rate of freedom from } \\
\text { progression to AP/BP, \% }(95 \% \mathrm{CI})\end{array}$} \\
\hline At 5 years & $96.3(94.1-98.6)$ & $97.8(96.0-99.5)$ & $92.2(89.1-95.4)$ \\
\hline At 10 years & $95.9(93.5-98.3)$ & $97.3(95.3-99.3)$ & $90.8(87.3-94.3)$ \\
\hline HR vs imatinib (95\% CI) & $0.45(0.22-0.92)$ & $0.28(0.12-0.66)$ & NA \\
\hline$P$ vs imatinib & 0.02 & $<0.005$ & NA \\
\hline Progression to AP, $n^{\mathrm{c}}$ & 6 & 4 & 11 \\
\hline \multicolumn{4}{|l|}{$\begin{array}{l}\text { Estimated rate of freedom from } \\
\text { progression to AP, \% (95\% CI) }\end{array}$} \\
\hline At 5 years & $98.2(96.6-99.8)$ & $98.5(97.0-100)$ & $97.1(95.1-99.1)$ \\
\hline At 10 years & 97.7 (95.9-99.5) & $98.5(97.0-100)$ & $95.5(92.9-98.2)$ \\
\hline HR vs imatinib ( $95 \% \mathrm{CI})$ & $0.54(0.20-1.46)$ & $0.36(0.11-1.12)$ & NA \\
\hline$P$ vs imatinib & 0.22 & 0.07 & NA \\
\hline Progression to $\mathrm{BP}, n^{\mathrm{c}}$ & 6 & 6 & 14 \\
\hline \multicolumn{4}{|l|}{$\begin{array}{l}\text { Estimated rate of freedom from } \\
\text { progression to } \mathrm{BP}, \%(95 \% \mathrm{CI})\end{array}$} \\
\hline At 5 years & $97.8(96.0-99.5)$ & $98.1(96.5-99.8)$ & $94.9(92.3-97.5)$ \\
\hline At 10 years & $97.8(96.0-99.5)$ & 97.7 (95.8-99.5) & $94.9(92.3-97.5)$ \\
\hline HR vs imatinib (95\% CI) & $0.42(0.16-1.09)$ & $0.41(0.16-1.08)$ & NA \\
\hline$P$ vs imatinib & 0.06 & 0.06 & NA \\
\hline \multicolumn{4}{|l|}{$\begin{array}{l}\text { Progression to AP/BP on study by age at } \\
\text { baseline }\end{array}$} \\
\hline Patients $<60$ years, $n^{\text {a }}$ & 223 & 228 & 224 \\
\hline $\begin{array}{l}\text { Progression to AP/BP in patients }<60 \\
\text { years, } n\end{array}$ & 7 & 6 & 20 \\
\hline $\begin{array}{l}\text { Estimated rate of freedom from } \\
\text { progression to AP/BP at } 10 \text { years, } \% \\
(95 \% \mathrm{CI})\end{array}$ & $96.7(94.3-99.1)$ & $97.2(94.9-99.4)$ & $90.4(86.3-94.4)$ \\
\hline Patients $\geq 60$ years, $n^{\mathrm{a}}$ & 59 & 53 & 59 \\
\hline $\begin{array}{l}\text { Progression to } \mathrm{AP} / \mathrm{BP} \text { in patients } \geq 60 \\
\text { years, } n\end{array}$ & 4 & 1 & 4 \\
\hline $\begin{array}{l}\text { Estimated rate of freedom from } \\
\text { progression to AP/BP at } 10 \text { years, \% } \\
(95 \% \mathrm{CI})\end{array}$ & $92.4(85.2-99.6)$ & $98.0(94.1-100)$ & $92.5(85.3-99.6)$ \\
\hline \multicolumn{4}{|l|}{$\begin{array}{l}\text { Progression to AP/BP on study by Sokal } \\
\text { risk score at baseline }\end{array}$} \\
\hline Patients in low Sokal risk group, $n^{\mathrm{a}}$ & 103 & 103 & 104 \\
\hline Low Sokal risk, $n$ & 2 & 1 & 1 \\
\hline $\begin{array}{l}\text { Estimated rate of freedom from } \\
\text { progression to AP/BP at } 10 \text { years, \% } \\
(95 \% \mathrm{CI})\end{array}$ & $97.8(94.8-100)$ & $99.0(97.1-100)$ & $98.8(96.4-100)$ \\
\hline $\begin{array}{l}\text { Patients in intermediate Sokal risk } \\
\text { group, } n^{\text {a }}\end{array}$ & 101 & 100 & 101 \\
\hline Intermediate Sokal risk, $n$ & 2 & 1 & 10 \\
\hline $\begin{array}{l}\text { Estimated rate of freedom from } \\
\text { progression to AP/BP at } 10 \text { years, \% } \\
(95 \% \mathrm{CI})\end{array}$ & $98.0(95.3-100)$ & $99.0(96.9-100)$ & $89.9(84.0-95.8)$ \\
\hline Patients in high Sokal risk group, $n^{\mathrm{a}}$ & 78 & 78 & 78 \\
\hline
\end{tabular}


Table 1 (continued)

\begin{tabular}{llll}
\hline & $\begin{array}{l}\text { Nilotinib 300 mg } \\
\text { twice daily }\end{array}$ & $\begin{array}{l}\text { Nilotinib 400 mg } \\
\text { twice daily }\end{array}$ & $\begin{array}{l}\text { Imatinib 400 mg } \\
\text { once daily }\end{array}$ \\
\hline $\begin{array}{l}\text { High Sokal risk, } n \\
\begin{array}{l}\text { Estimated rate of freedom from } \\
\text { progression to AP/BP at 10 years, } \%\end{array}\end{array}$ & 7 & 5 & 13 \\
$(95 \%$ CI $)$ & $90.3(83.5-97.2)$ & $92.6(86.3-98.9)$ & $80.9(71.4-90.4)$ \\
\hline
\end{tabular}

NA indicates not applicable.

${ }^{a}$ The evaluable $\mathrm{n}$ for each analysis.

bincludes progressions and CML-related deaths.

${ }^{\mathrm{c}}$ Includes progressions only.

Table 2 Estimated 10-year OS rates.

\begin{tabular}{|c|c|c|c|}
\hline & $\begin{array}{l}\text { Nilotinib } 300 \mathrm{mg} \\
\text { twice daily }\end{array}$ & $\begin{array}{l}\text { Nilotinib } 400 \mathrm{mg} \\
\text { twice daily }\end{array}$ & $\begin{array}{l}\text { Imatinib } 400 \mathrm{mg} \\
\text { once daily }\end{array}$ \\
\hline \multicolumn{4}{|l|}{ OS } \\
\hline All patients, $n$ & 282 & 281 & 283 \\
\hline OS events, $n$ & 32 & 24 & 29 \\
\hline \multicolumn{4}{|l|}{$\begin{array}{l}\text { Estimated rate of OS, \% } \\
(95 \% \mathrm{CI})\end{array}$} \\
\hline At 5 years & $93.7(90.8-96.6)$ & $96.3(94.0-98.5)$ & $91.8(88.5-95.1)$ \\
\hline At 10 years & $87.6(83.5-91.7)$ & $90.3(86.5-94.1)$ & $88.3(84.2-92.4)$ \\
\hline HR vs imatinib (95\% CI) & $1.07(0.64-1.76)$ & $0.79(0.46-1.36)$ & NA \\
\hline$P$ vs imatinib & 0.80 & 0.40 & NA \\
\hline \multicolumn{4}{|l|}{ OS on study by age at baseline } \\
\hline Patients $<60$ years, $n^{\mathrm{a}}$ & 223 & 228 & 224 \\
\hline $\begin{array}{l}\text { OS events in patients }<60 \\
\text { years, } n\end{array}$ & 15 & 11 & 21 \\
\hline $\begin{array}{l}\text { Estimated rate of OS at } 10 \\
\text { years, \% }(95 \% \mathrm{CI})\end{array}$ & $92.7(89.1-96.3)$ & $94.5(91.3-97.7)$ & $89.7(85.5-93.9)$ \\
\hline Patients $\geq 60$ years, $n^{\mathrm{a}}$ & 59 & 53 & 59 \\
\hline $\begin{array}{l}\text { OS events in patients } \geq 60 \\
\text { years, } n\end{array}$ & 17 & 13 & 8 \\
\hline $\begin{array}{l}\text { Estimated rate of OS at } 10 \\
\text { years, \% }(95 \% \mathrm{CI})\end{array}$ & $67.0(53.7-80.4)$ & $69.4(54.6-84.2)$ & $83.4(72.8-94.1)$ \\
\hline \multicolumn{4}{|c|}{ OS on study by Sokal risk score at baseline } \\
\hline $\begin{array}{l}\text { Patients in low Sokal risk } \\
\text { group, } n^{\mathrm{a}}\end{array}$ & 103 & 103 & 104 \\
\hline OS events, $n$ & 5 & 5 & 1 \\
\hline $\begin{array}{l}\text { Estimated rate of OS at } 10 \\
\text { years, \% }(95 \% \mathrm{CI})\end{array}$ & $94.7(90.3-99.2)$ & $94.1(89.1-99.1)$ & $98.8(96.4-100)$ \\
\hline $\begin{array}{l}\text { Patients in intermediate Sokal } \\
\text { risk group, } n^{\mathrm{a}}\end{array}$ & 101 & 100 & 101 \\
\hline OS events, $n$ & 12 & 9 & 14 \\
\hline $\begin{array}{l}\text { Estimated rate of OS at } 10 \\
\text { years, \% }(95 \% \mathrm{CI})\end{array}$ & $88.0(81.3-94.7)$ & $89.6(83.2-96.1)$ & $84.3(76.6-92.1)$ \\
\hline $\begin{array}{l}\text { Patients in high Sokal risk } \\
\text { group, } n^{\text {a }}\end{array}$ & 78 & 78 & 78 \\
\hline OS events, $n$ & 15 & 10 & 14 \\
\hline $\begin{array}{l}\text { Estimated rate of OS at } 10 \\
\text { years, \% }(95 \% \mathrm{CI})\end{array}$ & $76.5(65.9-87.1)$ & $85.9(77.3-94.6)$ & $78.9(68.8-88.9)$ \\
\hline
\end{tabular}

NA indicates not applicable.

${ }^{\text {a }}$ The evaluable $n$ for each analysis. 
Table 3 Estimated 10-year PFS rates.

\begin{tabular}{|c|c|c|c|}
\hline & $\begin{array}{l}\text { Nilotinib } 300 \mathrm{mg} \\
\text { twice daily }\end{array}$ & $\begin{array}{l}\text { Nilotinib } 400 \mathrm{mg} \\
\text { twice daily }\end{array}$ & $\begin{array}{l}\text { Imatinib } 400 \mathrm{mg} \\
\text { once daily }\end{array}$ \\
\hline \multicolumn{4}{|l|}{ PFS on study } \\
\hline All patients, $n$ & 282 & 281 & 283 \\
\hline PFS events, $n$ & 36 & 25 & 32 \\
\hline \multicolumn{4}{|c|}{ Estimated rate of PFS, \% (95\% CI) } \\
\hline At 5 years & $92.3(89.1-95.4)$ & $95.9(93.5-98.3)$ & $91.2(87.8-94.5)$ \\
\hline At 10 years & $86.2(81.9-90.5)$ & $89.9(86.1-93.8)$ & $87.2(83.0-91.4)$ \\
\hline HR vs imatinib (95\% CI) & $1.08(0.67-1.74)$ & $0.74(0.44-1.25)$ & NA \\
\hline$P$ vs imatinib & 0.75 & 0.27 & NA \\
\hline \multicolumn{4}{|l|}{ PFS on study by age at baseline } \\
\hline Patients $<60$ years, $n^{\mathrm{a}}$ & 223 & 228 & 224 \\
\hline $\begin{array}{l}\text { PFS events in patients }<60 \\
\text { years, } n\end{array}$ & 17 & 12 & 24 \\
\hline $\begin{array}{l}\text { Estimated rate of PFS at } 10 \\
\text { years, \% }(95 \% \mathrm{CI})\end{array}$ & $91.8(88.0-95.5)$ & $94.1(90.8-97.3)$ & $88.3(83.9-92.8)$ \\
\hline Patients $\geq 60$ years, $n^{\mathrm{a}}$ & 59 & 53 & 59 \\
\hline $\begin{array}{l}\text { PFS events in patients } \geq 60 \\
\text { years, } n\end{array}$ & 19 & 13 & 8 \\
\hline $\begin{array}{l}\text { Estimated rate of PFS at } 10 \\
\text { years, } \%(95 \% \mathrm{CI})\end{array}$ & $63.7(50.2-77.3)$ & $69.4(54.5-84.2)$ & $83.6(73.0-94.2)$ \\
\hline \multicolumn{4}{|c|}{ PFS on study by Sokal risk score at baseline } \\
\hline $\begin{array}{l}\text { Patients in low Sokal risk group, } \\
n^{\mathrm{a}}\end{array}$ & 103 & 103 & 104 \\
\hline PFS events, $n$ & 6 & 5 & 2 \\
\hline $\begin{array}{l}\text { Estimated rate of PFS at } 10 \\
\text { years, } \%(95 \% \mathrm{CI})\end{array}$ & 93.7 (88.9-98.6) & 94.1 (89.1-99.1) & $97.5(94.2-100)$ \\
\hline $\begin{array}{l}\text { Patients in intermediate Sokal } \\
\text { risk group, } n^{\text {a }}\end{array}$ & 101 & 100 & 101 \\
\hline PFS events, $n$ & 13 & 9 & 15 \\
\hline $\begin{array}{l}\text { Estimated rate of PFS at } 10 \\
\text { years, \% }(95 \% \mathrm{CI})\end{array}$ & $87.1(80.2-93.9)$ & $89.6(83.2-96.1)$ & $83.6(75.8-91.4)$ \\
\hline $\begin{array}{l}\text { Patients in high Sokal risk } \\
\text { group, } n^{\text {a }}\end{array}$ & 78 & 78 & 78 \\
\hline PFS events, $n$ & 17 & 11 & 15 \\
\hline $\begin{array}{l}\text { Estimated rate of PFS at } 10 \\
\text { years, \% }(95 \% \mathrm{CI})\end{array}$ & $74.0(63.2-84.8)$ & 84.6 (75.7-93.6) & $77.7(67.6-87.9)$ \\
\hline
\end{tabular}

NA indicates not applicable.

${ }^{a}$ The evaluable $n$ for each analysis. among patients $<60$ years old and $67.0 \%, 69.4 \%$, and $83.4 \%$, respectively, among patients $\geq 60$ years old (Table 2). The estimated 10-year PFS rates on study were $91.8 \%, 94.1 \%$, and $88.3 \%$, respectively, among patients $<60$ years old and $63.7 \%, 69.4 \%$, and $83.6 \%$, respectively, among patients $\geq 60$ years old (Table 3 ).

A total of 32, 23, and 29 deaths on study from any cause were reported in the nilotinib 300-mg twice-daily, nilotinib 400-mg twice-daily, and imatinib arms, respectively (Supplementary Table 2). One patient randomized to the imatinib arm died due to CML before the first treatment dose. Of all deaths on study, 16, 14, and 11 in the nilotinib 300-mg twice-daily, nilotinib 400-mg twice-daily, and imatinib arms, respectively, occurred after 5 years. The most common causes of death overall were CML, general disorders, and infections. The total number of deaths due to CML was 6, 5, and 15 in the nilotinib 300-mg twice-daily, nilotinib 400-mg twice-daily, and imatinib arms, respectively. Six deaths occurred on study due to CVEs, 3 in the nilotinib 300-mg twice-daily arm and 3 in the nilotinib 400-mg twice-daily arm, of which 2 and 3, respectively, occurred after 5 years. Two of the deaths due to CVEs occurred during or within 28 days of discontinuing core study treatment; 1 was due to cerebrovascular accident in the nilotinib 300-mg twice-daily arm, and 1 was due to myocardial infarction in the nilotinib 400-mg twice-daily arm. 

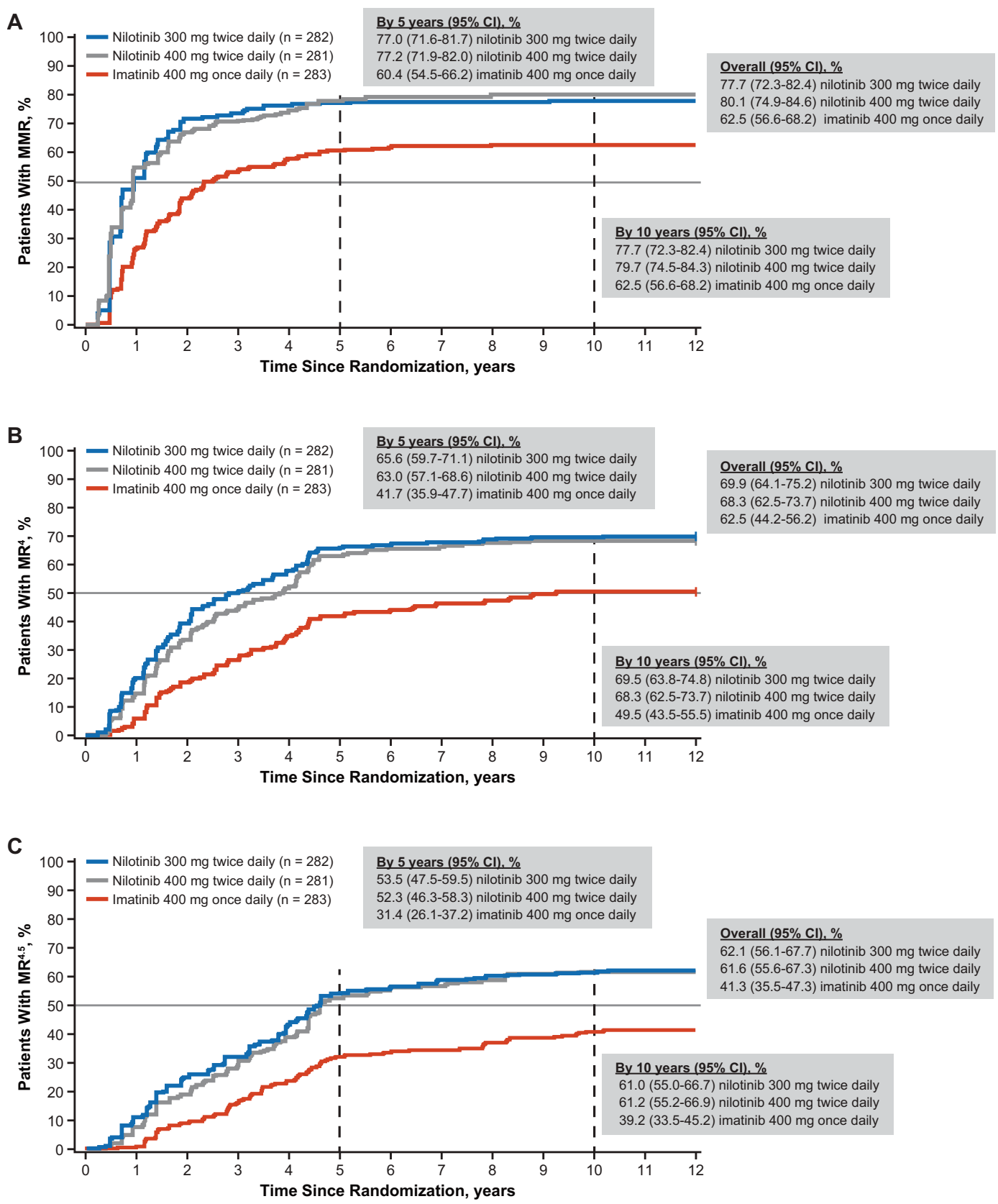

Fig. 2 Cumulative molecular response rates. Cumulative proportion of patients with (A) major molecular response (MMR; $B C R-A B L 1^{\mathrm{IS}} \leq$ $0.1 \%), \quad(\mathbf{B}) \mathrm{MR}^{4}\left(B C R-A B L 1^{\mathrm{IS}} \leq 0.01 \%\right)$, and (C) $\mathrm{MR}^{4.5}(B C R-$
$A B L 1^{\mathrm{IS}} \leq 0.0032 \%$ ). Cumulative $\mathrm{MMR}, \mathrm{MR}^{4}$, and $\mathrm{MR}^{4.5}$ results are an analysis of data from the core phase.

\section{Molecular response}

By 10 years, cumulative $\mathrm{MMR}, \mathrm{MR}^{4}$, and $\mathrm{MR}^{4.5}$ rates were higher with nilotinib than with imatinib (Fig. 2).

Change in molecular response from 5 to 10 years by molecular response at 5 years among the patients still on treatment at 5 years is shown in Fig. 1. In the nilotinib 300mg twice-daily arm, 6, 48, and 92 evaluable patients were not in MMR, $\mathrm{MR}^{4}$, and $\mathrm{MR}^{4.5}$, respectively, at 5 years while on treatment. Of those patients, $33.3 \%(2 / 6), 43.8 \%(21 / 48)$, and $38.0 \%$ (35/92) achieved MMR, $\mathrm{MR}^{4}$, and $\mathrm{MR}^{4.5}$, respectively, at 10 years while continuing the same treatment. In the nilotinib 400-mg twice-daily arm, 16, 66, and 105 evaluable patients were not in MMR, $\mathrm{MR}^{4}$, and $\mathrm{MR}^{4.5}$, respectively, at 5 years while on treatment. Of those patients, $43.8 \%$ (7/16), 37.9\% (25/66), and 28.6\% (30/105) achieved MMR, $\mathrm{MR}^{4}$, and $\mathrm{MR}^{4.5}$, respectively, at 10 years while continuing the same treatment. In the imatinib arm, 
Fig. 3 Cumulative rate of TFR eligibility. Patients were considered eligible for TFR if they achieved $\mathrm{MR}^{4.5}$ or better in any RQ-PCR assessment after $\geq 2$ years and then maintained sustained DMR for $\geq 1$ year, during which time no RQ-PCR assessment showed a response level worse than $\mathrm{MR}^{4}$, a maximum of 2 assessments occurred between $\mathrm{MR}^{4}$ and $\mathrm{MR}^{4.5}$, and the last assessment showed $\mathrm{MR}^{4.5}$ or better.

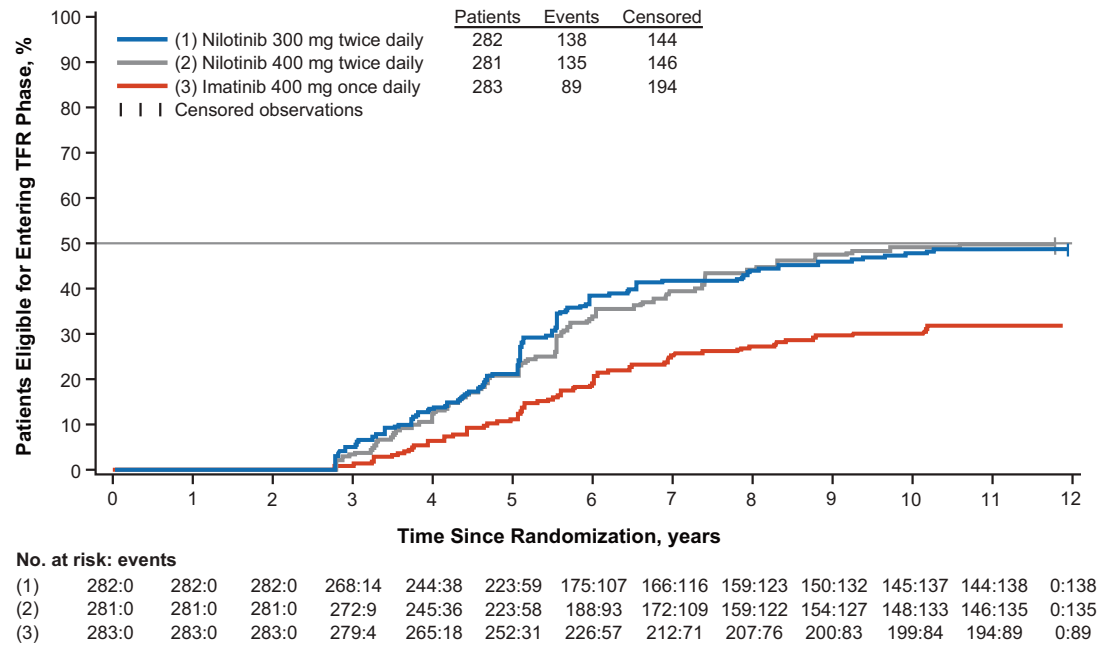

14, 65, and 97 evaluable patients were not in MMR, $\mathrm{MR}^{4}$, and $\mathrm{MR}^{4.5}$, respectively, at 5 years while on treatment. Of those patients, 50\% (7/14), 33.8\% (22/65), and $22.7 \%$ (22/97) achieved MMR, $\mathrm{MR}^{4}$, and $\mathrm{MR}^{4.5}$, respectively, at 10 years while continuing the same treatment.

\section{Combined analysis}

After combining data from the 2 nilotinib arms, 368 $(66.2 \%)$ and $146(52.1 \%)$ patients, respectively, in either nilotinib arm and in the imatinib arm remained on treatment for $\geq 5$ years, and 199 (35.8\%) and 90 (32.1\%) patients, respectively, remained on the same treatment for $\geq 10$ years, regardless of dose. Rates of MMR and $\mathrm{MR}^{4.5}$ were higher with nilotinib at 5 years (MMR, 63.6\%; $\mathrm{MR}^{4.5}, 31.1 \%$ ) and 10 years (MMR, 40.7\%; $\left.\mathrm{MR}^{4.5}, 27.0 \%\right)$ than with imatinib at 5 years (MMR, 49.1\%; $\mathrm{MR}^{4.5}, 19.8 \%$ ) and 10 years (MMR, 36.4\%; $\mathrm{MR}^{4.5}, 21.2 \%$ ). The median time to first MMR was shorter with nilotinib (8.41 months; range, 1.9-115.9) than with imatinib (14.16 months; range, 2.8-95.6). Similarly, the median time to first $\mathrm{MR}^{4.5}$ was shorter with nilotinib (37.65 months; range, 2.8-122.1) than with imatinib (41.63 months; range, 7.5-122.6).

\section{TFR eligibility}

By 10 years, more patients in each nilotinib arm than in the imatinib arm achieved sustained DMR (Supplementary Table 3). Rates of sustained DMR were analyzed in patient subsets based on Sokal risk at baseline, 3-month molecular response levels, and time to first $\mathrm{MR}^{4.5}$. In each Sokal risk group, rates of sustained DMR were higher with nilotinib than with imatinib.

In all 3 study arms, a higher proportion of patients with $B C R-A B L 1^{\text {IS }} \leq 10 \%$ at 3 months achieved sustained DMR compared with those who had $B C R-A B L 1^{\mathrm{IS}}>10 \%$ at
3 months; moreover, more patients in the nilotinib arms versus the imatinib arm achieved $B C R-A B L 1^{\mathrm{IS}} \leq 10 \%$ at 3 months, and the rate of sustained DMR among patients who achieved $B C R-A B L 1^{\mathrm{IS}} \leq 10 \%$ at 3 months was higher in the nilotinib arms versus the imatinib arm. In all arms, rates of sustained DMR were high among patients who achieved $\mathrm{MR}^{4.5}$ at any time; however, more patients in the nilotinib arms than the imatinib arm achieved $\mathrm{MR}^{4.5}$, and they did so earlier.

The estimated cumulative rates of TFR eligibility (estimated using ENESTfreedom criteria [18]) with nilotinib 300-mg twice-daily, nilotinib 400-mg twice-daily, and imatinib, respectively, at 5 years were $20.9 \%$ (95\% CI, $16.2-25.7 \%), 20.6 \%(15.9-25.4 \%)$, and $11.0 \%(7.3-14.6 \%)$ and 10 years were $48.6 \% \quad(42.7-54.4 \%), \quad 47.3 \%$ (41.5-53.2\%), and $29.7 \%$ (24.4-35.0\%) (Fig. 3).

\section{Safety}

The most common nonhematologic AEs of any cause in both nilotinib arms were rash and headache, while diarrhea and nausea were most common in the imatinib arm. In all 3 arms, most nonhematologic AEs were grade 1/2. Newly occurring or worsening grade 3/4 hematologic abnormalities were more common (specifically, decreased absolute lymphocytes and neutrophils) with imatinib than with nilotinib. Among the most common newly occurring or worsening grade $3 / 4$ biochemical abnormalities, elevations in glucose occurred in $24(8.6 \%), 21(7.6 \%)$, and $1(0.4 \%)$ patients in the nilotinib 300-mg twice-daily, nilotinib 400mg twice-daily, and imatinib arms, respectively; newly occurring or worsening grade 3/4 lipase elevations occurred in $29(10.4 \%), 30(10.8 \%)$, and $12(4.3 \%)$ patients, respectively (Supplementary Table 4).

Adverse events of interest such as severe fluid retention (including pleural effusion, pericardial effusion, 
Table 4 Cardiovascular events (CVEs).

\begin{tabular}{|c|c|c|c|}
\hline & $\begin{array}{l}\text { Nilotinib } 300 \mathrm{mg} \\
\text { twice daily }\end{array}$ & $\begin{array}{l}\text { Nilotinib } 400 \mathrm{mg} \\
\text { twice daily }\end{array}$ & $\begin{array}{l}\text { Imatinib } 400 \mathrm{mg} \\
\text { once daily }\end{array}$ \\
\hline CVEs, $n^{\mathrm{a}}$ & 279 & 277 & 280 \\
\hline \multicolumn{4}{|l|}{ Cumulative CVEs } \\
\hline All CVEs & $46(16.5)$ & $65(23.5)$ & $10(3.6)$ \\
\hline Ischemic heart disease & $22(7.9)$ & $36(13.0)$ & $8(2.9)$ \\
\hline $\begin{array}{l}\text { Peripheral arterial occlusive } \\
\text { disease }\end{array}$ & $18(6.5)$ & $20(7.2)$ & 0 \\
\hline $\begin{array}{l}\text { Ischemic cerebrovascular } \\
\text { disease }\end{array}$ & $13(4.7)$ & $21(7.6)$ & $1(0.4)$ \\
\hline Other CVEs & $4(1.4)$ & $4(1.4)$ & $1(0.4)$ \\
\hline \multicolumn{4}{|l|}{ CVEs by age at baseline } \\
\hline Patients $<60$ years, $n^{\mathrm{b}}$ & 221 & 227 & 221 \\
\hline All CVEs & $26(11.8)$ & $48(21.1)$ & $5(2.3)$ \\
\hline Ischemic heart disease & $12(5.4)$ & $27(11.9)$ & $5(2.3)$ \\
\hline $\begin{array}{l}\text { Peripheral arterial occlusive } \\
\text { disease }\end{array}$ & $9(4.1)$ & $15(6.6)$ & 0 \\
\hline $\begin{array}{l}\text { Ischemic cerebrovascular } \\
\text { disease }\end{array}$ & $7(3.2)$ & $16(7.0)$ & 0 \\
\hline Other CVEs & $3(1.4)$ & $3(1.3)$ & 0 \\
\hline Patients $\geq 60$ years, $n^{\mathrm{b}}$ & 58 & 50 & 59 \\
\hline All CVEs & $20(34.5)$ & $17(34.0)$ & $5(8.5)$ \\
\hline Ischemic heart disease & $10(17.2)$ & $9(18.0)$ & $3(5.1)$ \\
\hline $\begin{array}{l}\text { Peripheral arterial occlusive } \\
\text { disease }\end{array}$ & $9(15.5)$ & $5(10.0)$ & 0 \\
\hline $\begin{array}{l}\text { Ischemic cerebrovascular } \\
\text { disease }\end{array}$ & $6(10.3)$ & $5(10.0)$ & $1(1.7)$ \\
\hline Other CVEs & $1(1.7)$ & $1(2.0)$ & $1(1.7)$ \\
\hline
\end{tabular}

Values are $n(\%)$ unless otherwise noted.

${ }^{\mathrm{a}} \mathrm{A}$ patient with multiple occurrences of a CVE is counted only once in the CVE subcategory.

${ }^{\mathrm{b}}$ The evaluable $n$ for each analysis. and pulmonary edema) and pancreatitis were infrequent ( $<4 \%$ of patients in all arms). Any-grade hepatotoxicity occurred more frequently in the nilotinib arms (300-mg twice-daily, 48.4\%; 400-mg twice-daily, 53.1\%) than in the imatinib arm (17.5\%), and any-grade electrocardiogram QT prolongation was also more common with nilotinib (300-mg twice-daily, 6.8\%; 400-mg twice-daily, 7.9\%) than with imatinib (3.9\%); rates of any-grade and grade 3/4 AE groups of interest are shown in Supplementary Table 5.

CVEs were reported in 46 (16.5\%), 65 (23.5\%), and 10 (3.6\%) patients, respectively, in the nilotinib 300-mg twicedaily, nilotinib 400-mg twice-daily, and imatinib arms (Table 4). KM-estimated CVE rates were 10.6\%, 17.9\%, and $3.2 \%$, respectively, at 5 years and continued to increase to $24.8 \%, 33.4 \%$, and $6.3 \%$, respectively, at 10 years; however, the incidence of newly occurring CVEs displayed in a yearly time window seemed similar across years in all arms among patients on long-term treatment (Supplementary Fig. 3).
To determine the impact of preexisting cardiovascular risk on the development of CVEs during nilotinib or imatinib treatment, baseline Framingham general cardiovascular risk scores [19] were calculated for patients with no history of CVEs prior to study entry (nilotinib 300-mg twice-daily, $n=259$; nilotinib 400-mg twice-daily, $n=266$; imatinib, $n=264$ ). The majority of patients were in the low-risk category. Similar to trends observed before 5 years [5], in patients on treatment for $>5$ years, baseline Framingham general cardiovascular risk scores were predictive of patients' risk of developing a CVE during treatment. In patients on treatment for $>5$ years, CVEs occurred more frequently among patients in the high-risk (nilotinib 300-mg twice-daily, 33.3\%; nilotinib 400-mg twice-daily, 33.3\%; imatinib, $4.8 \%)$ and intermediate-risk $(28.0 \%, 48.5 \%$, $17.4 \%$, respectively) categories in each arm than in the lowrisk category $(8.7 \%, 15.2 \%, 1.1 \%$, respectively). In the lowrisk category, CVE rates after 5 years were higher than the rates before 5 years $(2.2 \%, 4.0 \%, 0.5 \%$, respectively) (Table 5). 


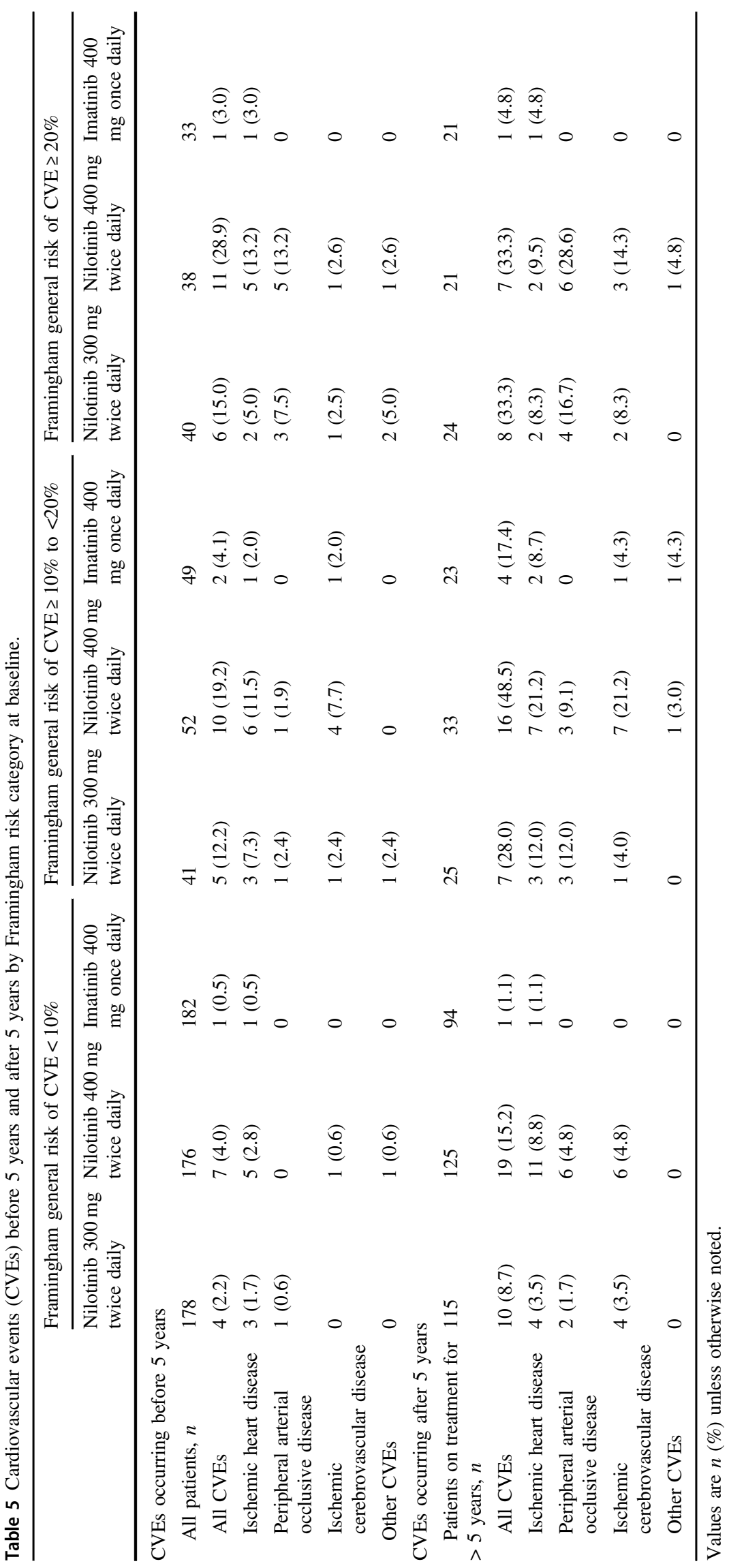




\section{Discussion}

With 10 years of follow-up in ENESTnd, the balance of benefits and risks of nilotinib versus imatinib in patients with newly diagnosed CML-CP can be thoroughly evaluated. Nilotinib demonstrated benefits over imatinib in several clinical patient outcomes, including higher cumulative molecular response rates, lower rates of progression to AP/BP and CML-related deaths, and increased eligibility for TFR.

The cumulative rates of MMR, $\mathrm{MR}^{4}$, and $\mathrm{MR}^{4.5}$ were higher by 5 years and by 10 years with nilotinib than with imatinib. In the combined analysis of the 2 nilotinib arms, response rates were higher at 5 years and 10 years with nilotinib versus imatinib, and patients in the nilotinib arms reached MMR and $\mathrm{MR}^{4.5}$ in a shorter time than those in the imatinib arm.

More patients in each nilotinib arm than in the imatinib arm achieved sustained DMR, both overall and independently of their Sokal risk group. The rates of TFR eligibility (estimated using ENESTfreedom criteria [18]) by 5 years with nilotinib were nearly double the rate achieved with imatinib, and although the rates increased in all 3 arms by 10 years, the imatinib arm remained below the nilotinib arms. The higher rate of sustained DMR by 10 years in patients with $B C R-A B L 1^{\mathrm{IS}} \leq 10 \%$ at 3 months versus those with $B C R-A B L 1^{\mathrm{IS}}>10 \%$ at 3 months, especially with nilotinib therapy, suggests that early molecular responses with nilotinib are associated with additional long-term benefits, including the possibility of attempting TFR.

Although mature PFS and OS rates were similar in all arms, including in patients who stayed on initial treatment, or were in follow-up or switched to second-line treatment during extension, subgroup analyses allowed identification of subsets of patients who had favorable outcomes. Rates of freedom from progression to AP/BP, OS, and PFS at 10 years among subsets of younger patients were numerically higher in both nilotinib arms versus the imatinib arm. In all 3 arms, the 10-year OS and PFS rates were substantially lower in the older patient subsets (showing poorer survival) than overall rates or rates in the younger patients (particularly in both nilotinib arms compared with imatinib), although these results should be interpreted with caution because the sample size was small for the older subset.

The overall frequency of nonhematologic AEs was similar with nilotinib and imatinib. Long-term follow-up confirms trends similar to those previously reported [5] in overall frequencies of AEs of interest for both nilotinib and imatinib.

Analyses of CVEs based on long-term follow-up showed a higher rate of CVEs with nilotinib versus imatinib. This result was consistent with earlier results from this study as well as other studies that have shown a risk of CVEs with second- and third-generation TKIs compared with imatinib [5, 20-22]. KM-estimated CVE rates were higher with nilotinib than with imatinib. Baseline Framingham general cardiovascular risk scores were predictive of a patient's risk of developing CVEs with nilotinib therapy. In an analysis of newly occurring CVEs displayed by a yearly time window, new CVEs continued to occur in patients receiving nilotinib at similar rates each year (Supplementary Fig. 3). CVEs occurred more frequently among patients in the Framingham high-risk and intermediate-risk categories than in the low-risk category, and new events continued to occur throughout a long treatment period. In Framingham lowrisk patients, the rates of CVEs after the first 5 years of treatment were higher on nilotinib than on imatinib, whereas patients in the low-risk category in all arms experienced few CVEs during the first 5 years [5]. Additionally, CVEs occurred more frequently in the nilotinib 400-mg twice-daily arm than in the other arms.

Despite specific efforts to address the key reversible risk factors, the risk of CVEs with nilotinib therapy beyond 5 years remains higher than with imatinib, including for patients in the Framingham low-risk category, who seem less tolerant to long-term treatment beyond 5 years. Hence, the benefit-risk balance for long-term treatment should be cautiously assessed, particularly in patients for whom TFR is not a feasible option. These patients must be informed on potential risks and closely monitored for any cardiovascular comorbidities during treatment with nilotinib.

Overall, efficacy and safety results from ENESTnd support the use of nilotinib 300-mg twice-daily as frontline therapy for patients with CML-CP for optimal long-term outcomes, including CML-related deaths, which continued to be numerically lower with nilotinib versus imatinib after 10 years of treatment. Further, no CML-related deaths were reported in the nilotinib 300-mg twice-daily arm beyond 5 years.

The positive benefit-risk balance is especially notable in the context of TFR as a treatment goal. The estimated rates of TFR eligibility were higher with nilotinib (at 5 and 10 years) than with imatinib, suggesting that frontline nilotinib therapy may be a superior choice for patients looking to achieve deeper molecular responses needed for attempting TFR or for patients who are aiming to achieve optimal long term outcomes in CML.

\section{Data availability}

Novartis is committed to sharing with qualified external researchers, access to patient-level data and supporting clinical documents from eligible studies. These requests are reviewed and approved by an independent review panel on the basis of scientific merit. All data provided are anonymized to respect the privacy of patients who have 
participated in the trial in line with applicable laws and regulations. This trial data availability is according to the criteria and process described on www.clinicalstudydata request.com.

Acknowledgements The ENESTnd study and work presented here were sponsored and funded by Novartis Pharmaceuticals Corporation. Financial support for medical editorial assistance was provided by Novartis. We thank Claire Nourry-Boulot (Novartis) for providing support and input on the analyses and Karen Kaluza Smith, PhD, and Rohini Roy, $\mathrm{PhD}$ (Nucleus Global), for medical editorial assistance with this manuscript.

\section{Compliance with ethical standards}

Conflict of interest HMK, Grants, honoraria: AbbVie, Agios, Amgen, Immunogen, Pfizer. Grants: Ariad, Astex, BMS, Cyclacel, Daiichi Sankyo, Jazz Pharmaceuticals, Novartis. Advisory boards: Actinium. Consulting: Novartis. Honoraria: Takeda. TPH, Grants, advisory boards, symposia: Novartis. Grants: BMS. RAL, Personal fees, clinical trials contracts: Novartis. D-WK, Grants: Novartis, BMS, Pfizer, ILYANG co. SI, none. PIC, Speaker, honoraria: Novartis, BMS, Pfizer, Incyte. GE, Personal fees, nonfinancial support: Novartis. Personal fees: BMS, Pfizer, Incyte. CB, Personal fees, speaker, advisory boards: Novartis. Personal fees, speaker: EMS. RP, none. REC, Grants, personal fees: Novartis. Grants, personal fees: BMS, Pfizer. Personal fees: Ariad/Incyte. VD, none. IWF, Grants, other funding: AbbVie, AstraZeneca, BeiGene, Gilead Sciences, Janssen, Juno Therapeutics, Kite Pharma, MorphoSys, Pharmacyclics, Roche, Seattle Genetics, Takeda, TG Therapeutics, Unum Therapeutics, Verastem. Other funding: Curio Science, Great Point Partners, Iksuda Therapeutics, Nurix Therapeutics, Yingli Pharmaceuticals. Grants: Acerta Pharma, Agios, ArQule, Calithera Biosciences, Celgene, Constellation Pharmaceuticals, Curis, F. Hoffmann-La Roche Ltd, Forma Therapeutics, Forty Seven, Genentech, IGM Biosciences, Incyte, Infinity Pharmaceuticals, Karyopharm Therapeutics, Loxo, Merck, Novartis, Pfizer, Portola Pharmaceuticals, Teva, Trillium Therapeutics, Triphase Research \& Development Corp., Rhizen Pharmaceuticals. SK, none. EM, none. MZ, none. IB, none. SC, Other funding: Novartis. KT, Novartis employee. PA, Novartis employee. GS, Personal fees: Novartis, BMS, ARIAD, Pfizer. AH, Research support, personal fees, nonfinancial support: Novartis. Research support, personal fees: BMS, Pfizer. Research support: Incyte.

Ethics ENESTnd was conducted in accordance with the principles of the Declaration of Helsinki and local laws and regulations. Written informed consent was obtained from each patient. The study protocol was approved by the appropriate review board or ethics committee for each center. All authors had access to the data and analyzed the data in collaboration with the sponsor.

Publisher's note Springer Nature remains neutral with regard to jurisdictional claims in published maps and institutional affiliations.

Open Access This article is licensed under a Creative Commons Attribution 4.0 International License, which permits use, sharing, adaptation, distribution and reproduction in any medium or format, as long as you give appropriate credit to the original author(s) and the source, provide a link to the Creative Commons license, and indicate if changes were made. The images or other third party material in this article are included in the article's Creative Commons license, unless indicated otherwise in a credit line to the material. If material is not included in the article's Creative Commons license and your intended use is not permitted by statutory regulation or exceeds the permitted use, you will need to obtain permission directly from the copyright holder. To view a copy of this license, visit http://creativecommons. org/licenses/by/4.0/.

\section{References}

1. Weisberg E, Manley PW, Breitenstein W, Bruggen J, CowanJacob SW, Ray A, et al. Characterization of AMN107, a selective inhibitor of native and mutant Bcr-Abl. Cancer Cell. 2005;7:129-41.

2. McArthur GA, Chapman PB, Robert C, Larkin J, Haanen JB, Dummer R, et al. Safety and efficacy of vemurafenib in BRAF (V600E) and BRAF(V600K) mutation-positive melanoma (BRIM-3): extended follow-up of a phase 3, randomised, openlabel study. Lancet Oncol. 2014;15:323-32.

3. Delord JP, Robert C, Nyakas M, McArthur GA, Kudchakar R, Mahipal A, et al. Phase I dose-escalation and -expansion study of the BRAF inhibitor encorafenib (LGX818) in metastatic BRAFmutant melanoma. Clin Cancer Res. 2017;23:5339-48.

4. Saglio G, Kim DW, Issaragrisil S, le Coutre P, Etienne G, Lobo C, et al. Nilotinib versus imatinib for newly diagnosed chronic myeloid leukemia. N Engl J Med. 2010;362:2251-9.

5. Hochhaus A, Saglio G, Hughes TP, Larson RA, Kim DW, Issaragrisil $\mathrm{S}$, et al. Long-term benefits and risks of frontline nilotinib vs imatinib for chronic myeloid leukemia in chronic phase: 5-year update of the randomized ENESTnd trial. Leukemia. 2016;30:1044-54.

6. Hughes TP, Hochhaus A, Kantarjian HM, Cervantes F, Guilhot F, Niederwieser D, et al. Safety and efficacy of switching to nilotinib $400 \mathrm{mg}$ twice daily for patients with chronic myeloid leukemia in chronic phase with suboptimal response or failure on front-line imatinib or nilotinib $300 \mathrm{mg}$ twice daily. Haematologica. 2014;99:1204-11.

7. Kantarjian HM, Hochhaus A, Saglio G, De Souza C, Flinn IW, Stenke L, et al. Nilotinib versus imatinib for the treatment of patients with newly diagnosed chronic phase, Philadelphia chromosome-positive, chronic myeloid leukaemia: 24-month minimum follow-up of the phase 3 randomised ENESTnd trial. Lancet Oncol. 2011;12:841-51.

8. Larson RA, Hochhaus A, Hughes TP, Clark RE, Etienne G, Kim DW, et al. Nilotinib vs imatinib in patients with newly diagnosed Philadelphia chromosome-positive chronic myeloid leukemia in chronic phase: ENESTnd 3-year follow-up. Leukemia. 2012;26:2197-203.

9. Bower H, Björkholm M, Dickman PW, Höglund M, Lambert PC, Andersson TM. Life expectancy of patients with chronic myeloid leukemia approaches the life expectancy of the general population. J Clin Oncol. 2016;34:2851-7.

10. Hochhaus A, Baccarani M, Silver RT, Schiffer C, Apperley JF, Cervantes F, et al. European LeukemiaNet 2020 recommendations for treating chronic myeloid leukemia. Leukemia. 2020;34:966-84.

11. Pinilla-Ibarz J, Sweet K, Emole J, Fradley M. Long-term BCRABL1 tyrosine kinase inhibitor therapy in chronic myeloid leukemia. Anticancer Res. 2015;35:6355-64.

12. NCCN Clinical Practice Guidelines in Oncology. Chronic Myeloid Leukemia. V3.2020. https://www.nccn.org/professionals/ physician_gls/pdf/cml.pdf. Accessed 7 July 2020.

13. Gepner AD, Korcarz CE, Colangelo LA, Hom EK, Tattersall MC, Astor $\mathrm{BC}$, et al. Longitudinal effects of a decade of aging on carotid artery stiffness: the multiethnic study of atherosclerosis. Stroke. 2014;45:48-53.

14. Kim MS, Kang SJ, Lee CW, Han S, Park DW, Lee SW, et al. Prevalence of coronary atherosclerosis in asymptomatic healthy 
subjects: an intravascular ultrasound study of donor hearts. J Atheroscler Thromb. 2013;20:465-71.

15. Wilke T, Mueller S, Groth A, Fuchs A, Seitz L, Kienhöfer J, et al. Treatment-dependent and treatment-independent risk factors associated with the risk of diabetes-related events: a retrospective analysis based on 229,042 patients with type 2 diabetes mellitus. Cardiovasc Diabetol. 2015;14:14.

16. Baccarani M, Deininger MW, Rosti G, Hochhaus A, Soverini S, Apperley JF, et al. European LeukemiaNet recommendations for the management of chronic myeloid leukemia: 2013. Blood. 2013;122:872-84.

17. Hochhaus A, Saussele S, Rosti G, Mahon FX, Janssen JJWM, Hjorth-Hansen $\mathrm{H}$, et al. Chronic myeloid leukaemia: ESMO clinical practice guidelines for diagnosis, treatment and follow-up. Ann Oncol. 2017;28:iv41-iv51.

18. Hochhaus A, Masszi T, Giles FJ, Radich JP, Ross DM, Casares MT, et al. Treatment-free remission following frontline nilotinib in patients with chronic myeloid leukemia in chronic phase: results from the ENESTfreedom study. Leukemia. 2017;31:1525-31.

19. D'Agostino RB Sr, Vasan RS, Pencina MJ, Wolf PA, Cobain M, Massaro JM, et al. General cardiovascular risk profile for use in primary care: the Framingham Heart Study. Circulation. 2008;117:743-53.

20. Cortes JE, Saglio G, Kantarjian HM, Baccarani M, Mayer J, Boque $\mathrm{C}$, et al. Final 5-year study results of DASISION: the dasatinib versus imatinib study in treatment-naive chronic myeloid leukemia patients trial. J Clin Oncol. 2016;34:2333-40.

21. Cortes JE, Jean Khoury H, Kantarjian H, Brummendorf TH, Mauro MJ, Matczak E, et al. Long-term evaluation of cardiac and vascular toxicity in patients with Philadelphia chromosomepositive leukemias treated with bosutinib. Am J Hematol. 2016;91:606-16.

22. Lipton JH, Chuah C, Guerci-Bresler A, Rosti G, Simpson D, Assouline $\mathrm{S}$, et al. Ponatinib versus imatinib for newly diagnosed chronic myeloid leukaemia: an international, randomised, openlabel, phase 3 trial. Lancet Oncol. 2016;17:612-21.

\section{Affiliations}

Hagop M. Kantarjian $\mathbb{1}^{1} \cdot$ Timothy P. Hughes ${ }^{2,3} \cdot$ Richard A. Larson $\mathbb{1}^{4} \cdot$ Dong-Wook Kim $\mathbb{1}^{5} \cdot$ Surapol Issaragrisil ${ }^{6}$. Philipp le Coutre $^{7}$. Gabriel Etienne ${ }^{8}$. Carla Boquimpani ${ }^{9,10} \cdot$ Ricardo Pasquini $^{11} \cdot$ Richard E. Clark $\mathbb{D}^{12}$. Viviane Dubruille ${ }^{13} \cdot$ Ian W. Flinn ${ }^{14} \cdot$ Slawomira Kyrcz-Krzemien $^{15} \cdot$ Ewa Medras $^{16} \cdot$ Maria Zanichelli $^{17}$. Israel Bendit $^{18} \cdot$ Silvia Cacciatore $^{19} \cdot$ Ksenia Titorenko $^{20} \cdot$ Paola Aimone $^{19} \cdot$ Giuseppe Saglio $^{21} \cdot$ Andreas Hochhaus $^{22}$

1 The University of Texas MD Anderson Cancer Center, Houston, TX, USA

2 South Australian Health and Medical Research Institute, Adelaide, SA, Australia

3 University of Adelaide, Adelaide, SA, Australia

4 Department of Medicine, Section of Hematology/Oncology, University of Chicago, Chicago, IL, USA

5 Seoul St. Mary's Hospital, College of Medicine, Catholic University of Korea, Seoul, South Korea

6 Faculty of Medicine, Siriraj Hospital, Mahidol University, Bangkok, Thailand

7 Charité - Universitätsmedizin Berlin, Berlin, Germany

8 Hematology Department, Institut Bergonié, Bordeaux, France

9 Hemorio, Institute of Hematology, Rio de Janeiro, Brazil

10 Oncoclínica Rio de Janeiro, Rio de Janeiro, Brazil

11 Universidade Federal do Paraná, Hospital de Clinicas, Curitiba, Paraná, Brazil

12 Royal Liverpool University Hospital, Liverpool, United Kingdom
13 Clinical Hematology, Nantes University Hospital, Nantes, France

14 Sarah Cannon Research Institute, Nashville, TN, USA

15 Department of Hematology and Bone Marrow Transplantation, Medical University of Silesia, Katowice, Poland

16 Department of Hematology, Blood Neoplasms and Bone Marrow Transplantation, Wroclaw Medical University, Wroclaw, Poland

17 Instituto de Tratamento do Câncer Infantil, Instituto da Criança, Hospital das Clínicas, Universidade de São Paulo, São Paulo, Brazil

18 Laboratory of Medical Investigation in Pathogenesis and Targeted Therapy in Onco-Immuno-Hematology (LIM-31), Department of Hematology, Hospital das Clínicas HCFMUSP, Faculdade de Medicina, Universidade de São Paulo, São Paulo, Brazil

19 Novartis Pharma AG, Basel, Switzerland

20 Novartis Pharmaceuticals Corporation, Moscow, Russian Federation

21 Division of Internal Medicine and Hematology, University of Turin, Turin, Italy

22 Universitätsklinikum Jena, Jena, Germany 